while and informative. Moreover, it sounds like fun!

IAN J. JACKSON

MRC Mammalian Development Unit,

Wolfson House,

(University College London),

4 Stephenson Way,

London NW1 $2 \mathrm{HE}, U K$

1. Flavell. A. Nature 320, 397 (1986).

Copeland, N.G.. Hutchinson, K.W. \& Jenkins. N.A. Cell 33, 379-387 (1983).

3. Jaenisch. R. et al. Cell 32, 209-216 (1983).

4. Wagner, E.R.. Covarrubias, L., Stewart, T.A. \& Mintz, B. Cell 35, 647-655 (1983)

Woychik. R.P., Stewart, T.A., Davis, L.G., D'Eustachio. P. \& Leder, P. Nature 318, 36-40 (1985)

6. Van Der Putten. H. et al. Proc. natn. Acad. Sci. U.S.A. 82 6148-6152 (1985)

7. Jenkins, N.A. \& Copeland, N.G. Cell 43, 811-819 (1985). 8. Palmiter, R.D. \& Brinster, R.L. Cell 41, 353-345 (1985).

\section{Initiating boiling with ice}

SIR-When an observation in the physical world appears to be paradoxical, running counter to one's intuition, experience and learning, it usually provides an opportunity to achieve some valuable scientific insight. Such a case began with the observation by one of us (R.L.D.) that a large spoon that had been kept in the freezer would initiate boiling in water that had been heated in a cup in a microwave oven, which the other one of us (R.E.A.) suggested might occur because crystals of ice initiate boiling in overheated water.

Water is said to be overheated or 'superheated' when its boiling temperature for a given pressure is surpassed without transformation to the vapour phase. This can be brought about by heating a drop of water as it rises in a heated column of oil. Using this technique, water can be heated to as high as $279.5^{\circ} \mathrm{C}$ at atmospheric pressure before explosive boiling occurs ${ }^{1}$. This extreme superheating occurs because there is no free vapour/liquid interace, the water being immersed in oil. Even if there is a free interface, significant superheating is possible ${ }^{2}$ because the internal temperatures can rise above the boiling temperature which occurs at the interface where vaporization occurs. (The true definition of boiling relates to vaporization at a flat liquid/vapour interface, and, therefore, is not defined by the onset of vapour bubbles.) 'Bumping' occurs when clean water is heated and boils unevenly but can be avoided by the presence of a boiling 'chip' or a piece of Teflon, which contains many gas-entrapping crevices.

We found that the temperature that could be achieved by tap water in a beaker heated on an oven-top burner was 100.75 $\pm 0.25^{\circ} \mathrm{C}$, close to the boiling temperature. But when tap water was heated in a microwave oven, the temperature measured by a thermocouple was briefly in excess of $110^{\circ} \mathrm{C}$ and there were more sustained periods of $105-106^{\circ} \mathrm{C}$. To ensure that our thermocouple did not trigger boiling, we put it in a glass well that contained cooking oil. The tip of the glass well was positioned in the centre of the tap water held in a Pyrex beaker. The leads to our thermocouple were not attached to the voltmeter while the microwave was running, because the radiation would cause spurious readings. Our chromel/ alumel thermocouple was calibrated with a crushed ice-water bath, and checked at the boiling temperature using water brought to a rolling boil (using a large chunk of Teflon).

Several kitchen objects were used to check the hypothesis that ice crystals nucleate boiling in ordinary tap water. When a stainless-steel or silver serving spoon was used, it would only nucleate boiling when cooled in a freezer (where some ice crystals could form). Glass, a screwdriver, and a plastic utensil behaved in the same way. If small boiling chips were added to the water before it was heated, we could not produce enough superheating, and inserted objects did not stimulate boiling.

Ice cubes themselves triggered a 'rolling' boil if the temperature rose above about $102^{\circ} \mathrm{C}$. At a superheat of about $10^{\circ} \mathrm{C}$ wove the boiling temperature, ice could nucleate boiling for 3-4 s. The time of boiling roughly scales to the number of degrees of superheat. Ice made with degassed water behaved in the same way as ice made with tap water saturated with gas.

It is quite clear that the mechanisms of the phenomena we observed are as follows: the microwave oven heats the water directly and the container indirectly, the opposite of what happens when heating by conduction with a burner. Therefore, the internal temperature can rise above the boiling temperature at positions away from the container's surface which tended to provide sites for boiling. Evaporation at the free surface does not occur rapidly enough to cool the bulk of the sample. When an ice cube is introduced, its creviced crystalline structures, which can hold gas or water vapour, stimulate film boiling on local parts of the surface of the ice cube. The vapour film acts as a partial thermal insulation, slowing down the heat transfer between the ice cube (at about $-15^{\circ} \mathrm{C}$ ) and the water (at $\left.110^{\circ} \mathrm{C}\right)$. When the water temperature immediately around the ice cube drops below $102^{\circ} \mathrm{C}$, or so, the observed boiling ceases.

When our experiments are repeated with water in a plastic cup, a much smaller degree of superheat is achieved, primarily because the water wets plastic much more poorly that it does Pyrex glass, and therefore boiling on the surfaces of plastic is much more active, cooling the interior and preventing significant superheating.

One word of caution. We used extremely fine, insulated thermocouple wire, which allowed us to close the microwave oven door and not risk radiation leakage. Similar precautions should be taken by those who desire to repeat our experiments.

Robert E. ApfeL

Department of Mechanical Engineering, Yale University,

New Haven

Connecticut 06520, USA

RichaRd L. DAY

Department of Pediatrics,

Yale University School of Medicine,

New Haven,

Connecticut 06510, USA

1. Apfel, R.E. Nature phys. Sci. 239,63-64 (1972)

2. Harvey, E.N. et al. J.Cell comp. Physiol. 24, 23-34 (1944).

\section{In defence of bacterial phylogeny}

SIR-In recent correspondence, Woese et $a l .{ }^{\prime}$ say that our differences on Archaebacteria eocytes and photocytes are semantic. Our differences are fundamental and are based on two contradictory evolutionary trees. If one tree is correct the other is not. These trees are our combined photocyte/eocyte tree $e^{2.3}$ and the tree of Woese'. Each relates all extant organisms.

The most widely used and accepted method for selecting a tree is parsimony analysis ${ }^{4}$. The four prokaryotic groups, halobacteria, eubacteria, methanogens and eocytes, can be topologically connected (by unrooted trees) in only three different ways. These correspond to our photocyte tree, to Woese's tree and to a third alternative, shown in Fig. 1. According to parsimony, a tree relating four taxa is supported if a given molecular property is found in two taxa while an altered version of the property is found in both of the other two. Thus "two-and-two" properties are valid. However, if a property is found only in one of the four groups, then it does not support any tree. Hence "three-and-one" properties are invalid.

All of the photocyte molecular properties listed in Table 1 below support the photocyte tree. All are two-and-two and hence are phylogenetically valid properties by the parsimony criteria. The list includes basic cellular properties such as membrane related components [tetraether lipids ${ }^{5}$ and fatty acid esters $\left.{ }^{6}\right]$, biochemical pathways [carotenoid synthesis ${ }^{7}$ and arginine deiminase pathways $\left.{ }^{8}\right]$ and bioenergetic components $\left[\mathrm{C}_{40}\right.$ and $\mathrm{C}_{50}$ carotenoids ${ }^{9}$ and $2 \mathrm{Fe}-2 \mathrm{~S}$ ferredoxin $\left.{ }^{10}\right]$ in addition to ribosomal RNA sequences and ribosome structure. Contrary to the implication of Woese et al. ${ }^{1}$, the eocytic $50 \mathrm{~S}$ lobes found in ribosomes of eocytes and systematically distributed within the methanogens ${ }^{2.11 .12}$ are also two-and-two. All molecular characters are the same for halobacteria and eubacteria and for methanogens and eocytes, hence they all support the photocyte tree. Many are 